\title{
Participación salarial y crecimiento económico en América Latina, 1950-2011
}

\author{
Germán Alarco Tosoni
}

RESUMEN

En este artículo se construyen las series de la participación salarial en el producto interno bruto (PIB) de 15 economías de América Latina y la correspondiente al conjunto de estas entre 1950-2010. Se determina, con diferentes metodologías, la tendencia no lineal de esta variable, corroborando la presencia de dos grandes ciclos. Se incluye una discusión de diversos autores, especialmente clásicos y postkeynesianos, que exploran la vinculación de esta variable con el nivel de actividad económica. Asimismo, se demuestra la pertinencia del enfoque postkeynesiano para explicar que las variaciones del PIB real están determinadas por la participación salarial, la formación bruta de capital y las exportaciones de bienes y servicios, entre las principales variables. Sin embargo, la contribución de la variación de la participación salarial al crecimiento del producto real es menos importante a partir de los años ochenta. 


\section{I}

\section{Introducción}

La vinculación de la distribución factorial del ingreso con el nivel de actividad y el crecimiento económico es antigua. Sus antecedentes se remontan a los economistas clásicos y se analizan al detalle en la escuela postkeynesiana. En los últimos tiempos, en la mayoría de las economías latinoamericanas, todo el esfuerzo se ha centrado en el análisis de la distribución personal del ingreso por hogares. Para la macroeconomía estándar, la posición en el proceso productivo (asalariados, trabajadores independientes, propietarios de los medios de producción y rentistas) no aporta al diagnóstico ni a las recomendaciones sobre la realidad. Asimismo, las estadísticas relativas a esta caracterización se han deteriorado. El reto de rehabilitar las teorías en que la distribución funcional del ingreso se considera como un tema relevante, parte de la necesidad de reconstruir los datos.

Este trabajo estadístico es precedido por el de Lindenboim (2008), quien integra parcialmente la información de la participación de los salarios en el producto respecto de un grupo de países desarrollados desde los años cincuenta, y para otros de la región desde 1980. La conclusión es clara en las primeras economías donde se observa el ascenso de esta participación hasta los años setenta, para luego mostrar su estancamiento o caída vinculada a la crisis del "fordismo", con la excepción de Dinamarca. En el caso de la región, solo se observa la tendencia descendente con oscilaciones particulares en cada economía. Únicamente Chile y Colombia presentan crecimientos sostenidos en algunos períodos determinados.

En la misma dirección, Neira Barría (2010) reconstruye la información sobre la participación de la masa salarial en el producto interno bruto (PIB) a costo de factores para 14 países y la agregada ponderada para América Latina, con el producto a paridad del poder adquisitivo en dólares constantes de 1970 entre 19502000 y las participaciones a partir de información censal,

\footnotetext{
$\square$ Se reconoce el apoyo de Favio Leiva Cárdenas y Brian Cevallos Fujiy como asistentes del proyecto. Se agradecen los comentarios de Patricia del Hierro Carrillo y las observaciones de los dictaminadores anónimos a una versión anterior de este artículo, si bien cualquier error u omisión que pudiera existir es de absoluta responsabilidad del autor. Se agradece también a Juan M. Graña por proporcionar la serie básica de la participación salarial respecto del producto en la Argentina.
}

incluidos los salarios de los trabajadores autónomos o independientes ${ }^{1}$. En el caso del conjunto, se concluye mediante la información básica sin procesamiento alguno una fase ascendente hasta mediados de los años sesenta, para luego caer a un valor mínimo (o sima) hacia 1983. Prosigue la evolución de la tasa de participación salarial en el producto con una fase de recuperación registrándose un punto máximo a mediados de los años noventa. Posteriormente se observa una tendencia descendente. Sin embargo, a juicio del autor, hay marcadas variaciones entre los países y dentro de estos.

La Organización Internacional del Trabajo (OIT, 2012) se halla abocada a este esfuerzo estadístico y analítico, aunque con información de países seleccionados desde los años setenta. Un análisis comparativo de la productividad y la participación salarial en América Latina por subregiones entre 2000-2010 se encuentra en CEPAL/ OIT (2012). Existen otros trabajos históricos en que se abordan períodos más largos desde el siglo XIX para países específicos (Argentina, Brasil y México (Frankema, 2009), donde se ubica una sima previa alrededor de la Primera Guerra Mundial), o para los países del Cono Sur, determinándose una tendencia ascendente en la desigualdad entre 1870 y 1920 (Bértola y otros, 2008).

El objetivo del presente artículo es revisar la evolución de la participación de los salarios en el PIB de América Latina a partir de la reconstrucción de la información estadística, correlacionándola con la evolución del PIB real, a fin de evaluar cómo esta última variable es explicada por la participación salarial y otros componentes de la demanda agregada de acuerdo con el enfoque postkeynesiano. Los principales interrogantes que surgen son: ¿cuál es la evolución de la participación salarial?, ¿cómo se vincula dicha participación con la evolución del PIB real?, ¿cuáles son los diferentes enfoques teóricos que relacionan la participación salarial con el nivel de actividad y el crecimiento económico?, ¿en qué consiste el enfoque postkeynesiano para evaluar la vinculación entre estas variables?, ¿es válido este último enfoque para analizar la evolución del crecimiento de América Latina?

\footnotetext{
1 Los que tradicionalmente están incluidos en el excedente de explotación y para lo cual Neira Barría supone la misma retribución media que a los trabajadores asalariados, excluidos los trabajadores familiares no remunerados y otros no remunerados.
} 
Este artículo presenta siete secciones, incluidas la introducción, las conclusiones y el anexo metodológico. En la segunda sección se brinda la información básica sobre la participación salarial en las diferentes economías latinoamericanas, destacándose que no es plenamente homogénea en cuanto a las fechas de inicio y terminación. Se presentan las características básicas para cada país y el conjunto de América Latina. En la tercera sección se revisan algunos de los principales aportes teóricos en relación con las variables analizadas. Esta revisión se inicia brevemente con algunos economistas clásicos, abordando la problemática macroeconómica con Keynes, Kalecki y algunos postkeynesianos. La cuarta sección se refiere a la presentación del modelo básico en la lógica postkeynesiana, en que se considera la participación de los salarios como un elemento relevante para explicar el nivel y las variaciones del producto real. En la quinta sección se analizan las relaciones de causalidad entre la participación salarial, el PIB y la tasa de crecimiento del producto mediante una evaluación empírica. En la sexta sección se entregan las conclusiones del estudio y en la séptima se agrega un anexo metodológico.

Dentro de los alcances y limitaciones del presente estudio, debe destacarse que no se realiza un análisis detallado de cada economía considerada. La perspectiva del análisis es macroeconómica, omitiéndose factores de carácter estructural y sociopolíticos particulares de cada economía. No se analiza la problemática relativa a los trabajadores independientes urbanos y rurales que podrían tener una condición práctica similar a la de los asalariados. No se realiza una introducción en los temas relacionados con la teoría del valor, ni en su vinculación con los precios y la distribución del ingreso. Tampoco se aborda la discusión teórica y la evaluación estadística de la curva de Kuznets, que considera la relación entre desigualdad personal del ingreso y crecimiento económico. Ni se efectúa un análisis específico para determinar si el régimen de demanda está basado en los salarios o en las ganancias.

\section{II}

\section{Estadística básica}

La variable principal del análisis es la participación salarial en el PIB a precios corrientes, que se obtiene del cociente entre la información nominal para cada país y año y el producto correspondiente. Se considera la información estadística para 15 países de la región entre 1950 y 2011 , aunque debe señalarse que el período no es homogéneo en todos los casos, ya que la información es escasa para los años cincuenta. Se comprende a la Argentina (19502011), Bolivia (Estado Plurinacional de) (1960-2011), el Brasil (1950-2011), Chile (1950-2010), Colombia (1950-2010), Costa Rica (1953-2011), el Ecuador (1953-2011), El Salvador (1960-2011), Honduras (19502011), México (1950-2011), Panamá (1950-2011), el Paraguay (1962-2010), el Perú (1950-2011), el Uruguay (1955-2010) y Venezuela (República Bolivariana de) (1957-2011). No se considera a Guatemala, Nicaragua y la República Dominicana porque la información es muy fragmentada.

La primera fuente de información fue el Anuario Estadístico de América Latina y el Caribe para diversos años, publicado por la Comisión Económica para América Latina y el Caribe (CEPAL), como también sus estadísticas electrónicas (CEPAL, 2013) a partir de 1988. Cuando esta información no fue suficiente, se consideró la proporcionada por la Organización Internacional del
Trabajo (OIT) y de inmediato la presentada por fuentes nacionales en cada caso (primero la oficial o, en su defecto, la desarrollada por terceros sobre la base de dicha información). Solo en el caso extremo en que no se contó con esta información local primaria o secundaria, se recurrió nuevamente a un procedimiento mediante el cual se generó esta participación $(w)$ en años particulares a partir de los salarios reales promedio $\left(W_{t}\right)$, la población asalariada $\left(L_{t}\right)^{2}$ y el PIB real $\left(Y_{t}\right)$. En todos los casos, se ha tenido especial cuidado con el engarce de las diferentes series estadísticas, considerando siempre la fuente más reciente. De acuerdo con lo anterior, la ecuación (1) expresa el cálculo de la participación salarial en el PIB.

$$
w_{t}=\frac{\left(W_{t} L_{t}\right)}{Y_{t}}
$$

Aplicando diferencias entre el año $t$ y el $t-1$ y dividiendo entre $w_{t-1}$, la tasa de crecimiento de la participación de los salarios en el $\mathrm{PIB}^{3}$ se muestra en

\footnotetext{
${ }^{2}$ Excepcionalmente, se utiliza la población ocupada cuando no hay información sobre la población asalariada.

${ }^{3}$ Bajo los supuestos de que los salarios promedio son representativos de la estructura salarial del país en cuestión y que el deflactor del PIB es similar al índice de precios que se emplea para convertir los salarios nominales a reales.
} 
la ecuación (2), donde $\gamma_{x t}$ es la tasa de crecimiento de la variable $x$ en el año $t$. De esta forma, se cuenta con una expresión que permite tener una aproximación a lo sucedido en los años en que no se tiene información, a partir del valor del año anterior. Los detalles de la información por países se muestran en el anexo al final de este documento.

$$
\frac{\Delta w_{t}}{w_{t-1}}=\frac{\left(1+\gamma_{w_{t}}\right)\left(1+\gamma_{L_{t}}\right)}{1+\gamma_{Y_{t}}}-1
$$

En el cuadro 1 se muestran algunas variables relativas a las series de la participación salarial respecto del PIB para los diferentes países de América Latina y la correspondiente a la región durante el período $1950-2010^{4}$. En primer lugar, se presentan el número de observaciones, la media, la desviación estándar y el coeficiente de variación ${ }^{5}$. A continuación se señalan el valor máximo

\footnotetext{
${ }^{4}$ Es el caso de la Argentina, el Brasil, Chile, Colombia, Honduras, México, Panamá y el Perú, que representan entre el $80 \%$ y el $92 \%$ del producto regional de los 15 países seleccionados en 1960 y 1994, respectivamente. ${ }^{5}$ Como es sabido, el coeficiente de variación corresponde al cociente entre la desviación estándar y la media, durante el período considerado. Se reconoce que este puede variar en cada economía y período determinado, pero su análisis pormenorizado correspondería a una investigación fuera de los alcances de este estudio.
}

y el valor mínimo, así como sus correspondientes fechas de ocurrencia. Finalmente, en el cuadro 1 se muestra el indicador de tendencia móvil ${ }^{6}$ y el número de ciclos completos luego de aplicar el filtro de Hodrick-Prescott para calcular las tendencias no lineales.

Los promedios más altos de la participación salarial corresponden a Panamá, Costa Rica, Honduras, el Brasil, la Argentina, el Uruguay y Chile; mientras que el Ecuador, El Salvador y el Perú tienen los coeficientes más bajos. Bolivia (Estado Plurinacional de), Colombia, México, el Paraguay y Venezuela (República Bolivariana de) se ubican a nivel intermedio. Sin embargo, Panamá, el Ecuador, El Salvador, el Perú, la Argentina, el Uruguay y Venezuela (República Bolivariana de) registran una desviación estándar más alta, en comparación con Costa Rica y el Brasil que presentan las menores desviaciones estándar. En cuanto al coeficiente de variación, resulta evidente que los más estables corresponden a Costa Rica, el Brasil y el Paraguay, mientras que los más inestables

${ }^{6}$ Los resultados del indicador de tendencia $\varnothing=\frac{\sum_{n-9}^{n} X_{i}}{\sum_{1}^{10} X_{i}}$ corresponden al cociente del último resultado de la media móvil (tamaño 10) sobre el primero. Si el cociente fuera alrededor de uno, la serie tendría una tendencia constante. Mientras que si fuera mayor que uno, sería creciente y si fuese menor que uno, decreciente.

CUADRO 1

Principales características de la participación salarial en el PIB de América Latina

\begin{tabular}{|c|c|c|c|c|c|c|c|c|c|c|c|}
\hline País & Cobertura & $\begin{array}{c}\mathrm{N}^{\circ} \text { de } \\
\text { observaciones }\end{array}$ & $\bar{X}$ & $\sigma$ & $\frac{\sigma}{\bar{X}}$ & $\begin{array}{l}\text { Valor } \\
\text { máximo }\end{array}$ & $\begin{array}{l}\text { Fecha del } \\
\text { máximo }\end{array}$ & $\begin{array}{l}\text { Valor } \\
\text { mínimo }\end{array}$ & $\begin{array}{l}\text { Fecha del } \\
\text { mínimo }\end{array}$ & $\begin{array}{l}\text { Indicador de } \\
\text { tendencia media } \\
\text { móvil }(\mathrm{t}=10)\end{array}$ & Ciclos \\
\hline $\begin{array}{l}\text { Argentina } \\
\text { Bolivia (Estado }\end{array}$ & $1950-2011$ & 62 & 39,51 & 5,46 & 0,14 & 48,79 & 1974 & 28,06 & 1989 & 0,79 & 2 \\
\hline Plurinacional de) & $1960-2011$ & 52 & 33,98 & 3,88 & 0,11 & 43,12 & 1984 & 24,13 & 1986 & 0,79 & 1 \\
\hline Brasil & $1950-2011$ & 62 & 43,11 & 2,46 & 0,06 & 48,27 & 1957 & 39,31 & 2004 & 0,92 & 2 \\
\hline Chile & $1950-2010$ & 61 & 38,17 & 3,79 & 0,10 & 52,19 & 1972 & 30,88 & 1988 & 1,02 & 2 \\
\hline Colombia & $1950-2010$ & 61 & 36,82 & 3,35 & 0,09 & 44,07 & 1993 & 31,67 & 2008 & 0,95 & 1 \\
\hline Costa Rica & $1953-2010$ & 58 & 46,95 & 1,96 & 0,04 & 50,57 & 1990 & 39,10 & 1982 & 1,02 & 1 \\
\hline Ecuador & 1953-2011 & 60 & 26,15 & 7,19 & 0,28 & 37,95 & 2007 & 11,51 & 1999 & 1,08 & 1 \\
\hline El Salvador & 1960-2011 & 52 & 30,67 & 6,81 & 0,22 & 41,91 & 1981 & 15,80 & 1960 & 1,47 & 1 \\
\hline Honduras & $1950-2011$ & 62 & 43,31 & 3,52 & 0,08 & 50,36 & 1986 & 35,04 & 1953 & 1,15 & 1 \\
\hline México & $1950-2011$ & 62 & 32,58 & 3,57 & 0,11 & 40,26 & 1976 & 26,84 & 1987 & 0,96 & 2 \\
\hline Panamá & $1950-2011$ & 62 & 50,76 & 11,48 & 0,23 & 67,41 & 1969 & 30,15 & 2011 & 0,53 & 2 \\
\hline Paraguay & $1962-2010$ & 49 & 33,70 & 3,03 & 0,09 & 38,73 & 2000 & 24,34 & 1990 & 0,94 & 1 \\
\hline Perú & $1950-2011$ & 62 & 31,60 & 6,62 & 0,21 & 41,15 & 1958 & 20,91 & 2008 & 0,61 & 1 \\
\hline Uruguay & 1955-2011 & 57 & 39,37 & 5,68 & 0,14 & 50,43 & 1963 & 27,75 & 1984 & 0,76 & 2 \\
\hline $\begin{array}{l}\text { Venezuela } \\
\text { (República }\end{array}$ & & & & & & & & & & & \\
\hline Bolivariana de) & $1957-2010$ & 54 & 37,40 & 5,43 & 0,15 & 46,90 & 1960 & 25,52 & 1996 & 0,72 & 2 \\
\hline América Latina & $1950-2010$ & 61 & 38,76 & 2,02 & 0,052 & 41,70 & 1967 & 33,69 & 2004 & 0,88 & 2 \\
\hline
\end{tabular}

Fuente: elaboración propia sobre la base de Banco Mundial, Comisión Económica para América Latina y el Caribe (CEPAL), Organización Internacional del Trabajo (OIT) e instituciones de los respectivos países.

PIB: producto interno bruto. 
son los del Ecuador, Panamá, El Salvador y el Perú. Las fechas en que los diversos países lograron la mayor participación salarial varían en el tiempo.

Los valores mínimos tienden a producirse a partir de la crisis de la deuda de los años ochenta. En los casos de Honduras y El Salvador, se registran a finales de la década de 1950 e inicios de los años sesenta. Cuando se trata de los valores máximos, estos corresponden tanto a los momentos en que los procesos de industrialización mediante sustitución de importaciones fueron más intensos: Brasil, 1957; Perú, 1958; Uruguay, 1963, y Venezuela (República Bolivariana de), 1960, como a coyunturas sociopolíticas determinadas en favor de los trabajadores: Argentina, 1974; Bolivia (Estado Plurinacional de), 1984; Chile, 1972; Colombia, 1993; Costa Rica, 1990; Ecuador, 2007; El Salvador, 1981; Honduras, 1986; México, 1976; Panamá, 1969, y Paraguay, 2000.

Luego de aplicar las técnicas antes mencionadas, se determinan economías cuya tendencia en el largo plazo es más o menos constante en el tiempo, las que tienen una tendencia ascendente y la mayoría con tendencia descendente en el largo plazo. De todo el grupo, solo Honduras tiene una tendencia ascendente en el tiempo, ya que en los casos del Ecuador y El Salvador el indicador muestra un valor elevado, pero extremadamente cíclico. Los países con una tendencia más o menos constante en el tiempo son el Brasil, Chile, Colombia, Costa Rica y, en menor medida, México y el Paraguay. El último grupo está conformado por aquellos que tienen una tendencia descendente, donde los países de evolución más negativa corresponden a Panamá y el Perú, seguidos por la Argentina, Bolivia (Estado Plurinacional de), el Uruguay y Venezuela
(República Bolivariana de). A pesar de lo anterior, en muchas de las economías también se observan uno o dos ciclos completos en el período bajo análisis. Con dos ciclos destacan la Argentina, el Brasil, Chile, México, Panamá, el Uruguay y Venezuela (República Bolivariana de), mientras que en el resto de los países solo se advierte un ciclo completo o una situación menos definida.

En el gráfico 1 se aprecia la participación salarial respecto del PIB de las 15 economías analizadas a partir de la información original corregida por el filtro de Hodrick-Prescott, útil para determinar la tendencia no lineal de esas series estadísticas. En el gráfico 1 se presentan los resultados por grupos de países: economías de mayor tamaño, de tamaño intermedio, de menor tamaño y las centroamericanas. $\mathrm{Al}$ respecto, una primera observación que salta a la vista es que los niveles y fluctuaciones son diferentes entre los distintos países, lo que refleja la complejidad de los factores estructurales vinculados a los modelos de acumulación, económicos, sociales y políticos que determinan las participaciones en el PIB, aunque se observan en conjunto los valores máximos y mínimos de dicha participación señalados en párrafos anteriores. En la Argentina los ciclos son más pronunciados respecto del Brasil, lo que difiere de lo ocurrido en México. En el segundo grupo de economías resaltan la tendencia descendente en el Perú luego de su nivel máximo en la década de 1970, la naturaleza cíclica en Chile, y los casos de Colombia y Venezuela (República Bolivariana de) con niveles máximos en los años ochenta y sesenta, respectivamente. Del grupo de las economías latinoamericanas de menor tamaño destaca la baja variabilidad de Bolivia (Estado Plurinacional de), mientras que esta es más pronunciada en el Ecuador

GRÁFICO 1

\section{Participación salarial respecto del PIB corregida mediante filtro de Hodrick-Prescott, 1950-2010 \\ (En porcentajes del producto interno bruto $(P I B))$}

Economías de mayor tamaño

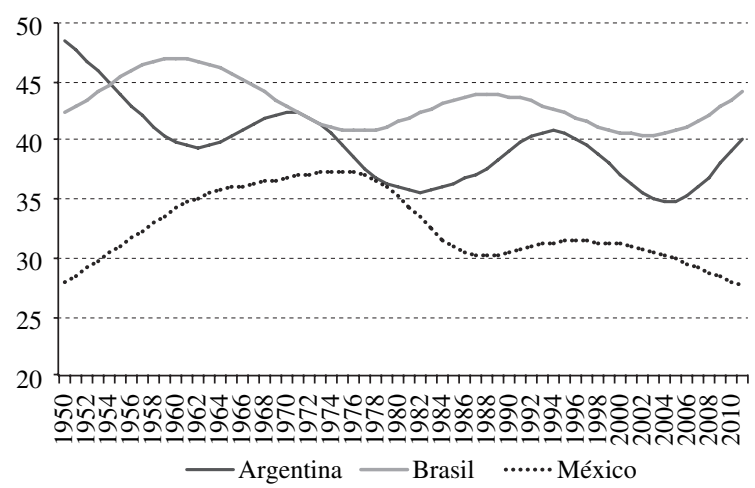

Economías de tamaño intermedio

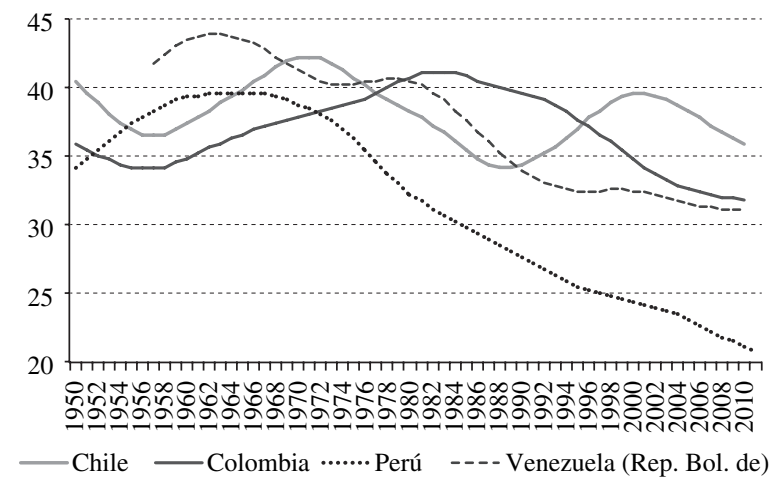


Economías de menor tamaño

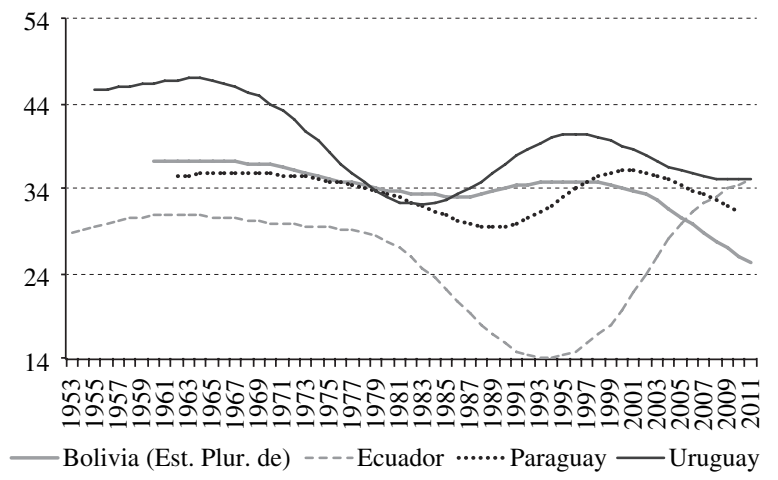

Economías centroamericanas

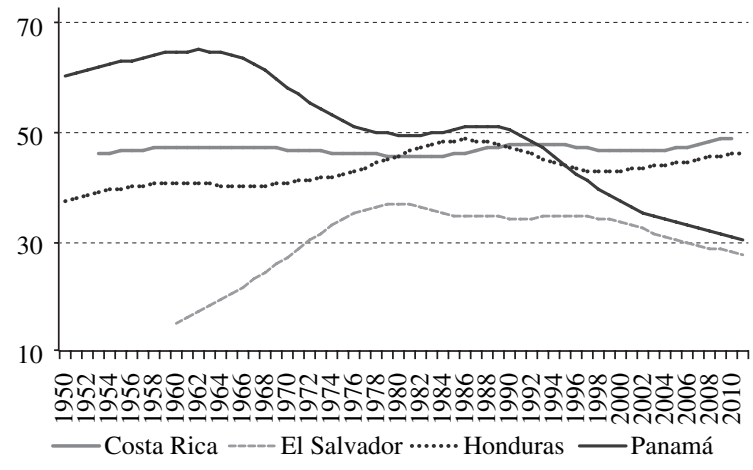

Fuente: elaboración propia sobre la base de Banco Mundial, Comisión Económica para América Latina y el Caribe (CEPAL), Organización Internacional del Trabajo (OIT) e instituciones de los respectivos países.

PIB: producto interno bruto.

de acuerdo con su información oficial. Por último, en el caso de las economías centroamericanas destaca la menor tendencia cíclica de Costa Rica, seguida por la de Honduras. La información es más variable en el caso de Panamá y El Salvador, referida a un período de tiempo más reducido.

La serie relativa a América Latina entre 1950-2010, ponderada con el PIB nominal en dólares corrientes ${ }^{7}$, evidencia una participación salarial promedio de $38,8 \%$, con una reducida desviación estándar solo ligeramente superior a la de Costa Rica. Asimismo, el coeficiente de variabilidad de la información es reducido, mostrando un valor máximo de $41,7 \%$ en 1967 , período en que las diversas economías regionales se encontraban en la fase de industrialización mediante sustitución de importaciones. En el otro extremo, el valor mínimo fue de $33,7 \%$ en 2004, que implica una variación negativa de ocho puntos porcentuales con relación a su valor máximo. De igual modo, se identifican dos ciclos completos para la serie de 61 años y una tendencia negativa de acuerdo con el indicador de los promedios móviles inferior a uno.

En el gráfico 2 se observa la evolución de la serie original de la participación salarial en el PIB y los diversos resultados como tendencia no lineal de conformidad

\footnotetext{
7 Con serie del Banco Mundial a partir de 1960 y de la CEPAL para el período 1950-1960.
}

con el filtro de Hodrick-Prescott, el indicador kernel de Epanechnikov ${ }^{8}$ y el promedio móvil decenal. Al respecto, se constata que las mayores participaciones se logran a finales de la década de 1960 e inicios de los años setenta y mediados de los años noventa, siendo los valores del primer ciclo superiores a los del segundo. Por el contrario, los períodos de menor participación corresponden a la crisis de la deuda de los años ochenta y mediados del primer quinquenio de la década inicial del siglo XXI, debido al mayor impacto de la crisis argentina. Asimismo, debe comentarse que a partir del segundo quinquenio de la primera década del presente siglo se observa una tendencia creciente en la participación de los salarios en el PIB, a causa de la mayor contribución a ese aumento de la Argentina y el Brasil. La aportación positiva del resto de los países es mínima (Colombia y Honduras) y negativa en los países restantes (Chile, México, Panamá y Perú). En el largo plazo, las economías que contribuyen a que la participación salarial de América Latina sea más elevada son las de la Argentina y del Brasil. En el promedio se ubica Chile, mientras que Colombia, México, Panamá y el Perú tienden a aminorarla.

\footnotetext{
${ }^{8}$ En este caso, una media móvil de 11 ventanas cuyos ponderadores provienen de una distribución de probabilidad simétrica que está en función del número de ventanas. La serie de coeficientes es la siguiente: $\{0,04 ; 0,07 ; 0,09 ; 0,11 ; 0,12 ; 0,13 ; 0,12 ; 0,11 ; 0,09 ; 0,07$, y 0,04$\}$.
} 


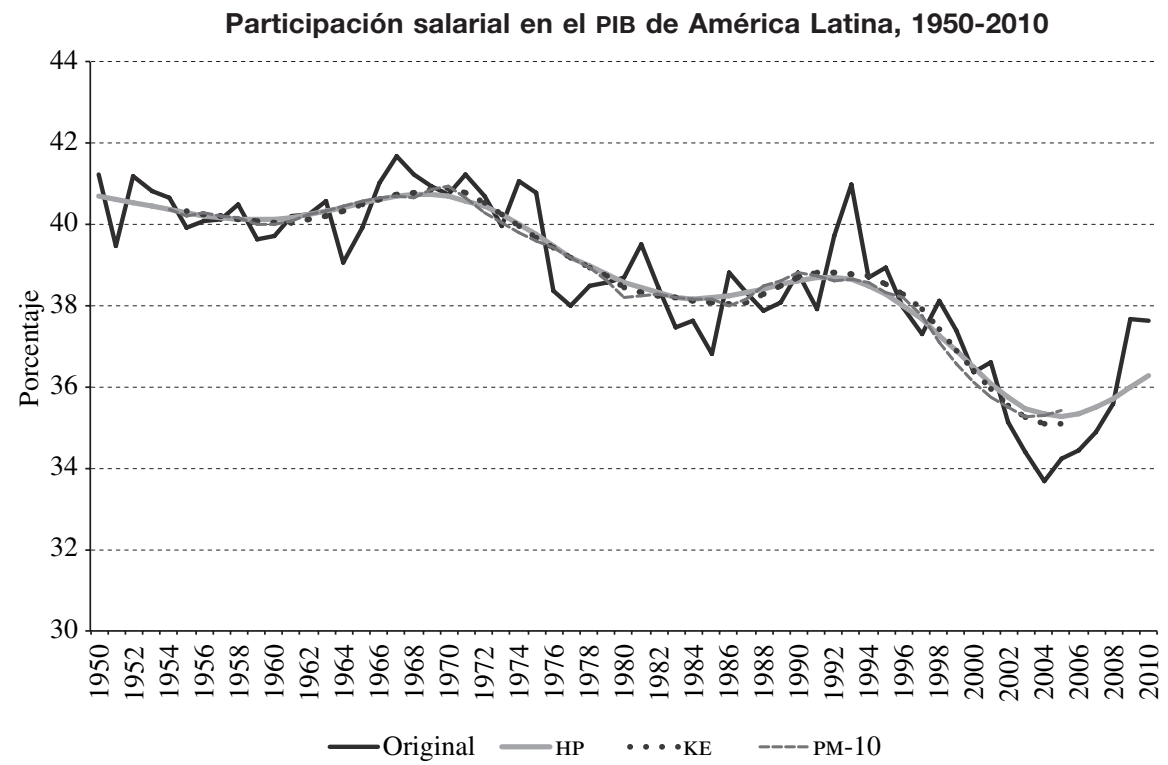

Fuente: elaboración propia sobre la base de Banco Mundial, Comisión Económica para América Latina y el Caribe (CEPAL), Organización Internacional del Trabajo (OIT) y diversas fuentes locales.

PIB: producto interno bruto.

HP: Hodrick-Prescott.

KE: kernel de Epanechnikov.

PM-10: promedio móvil decenal.

\section{III}

\section{Aportes teóricos en el transcurso del tiempo}

Smith (1987, págs. 76-77), como defensor de la mejora de las condiciones de vida de los perceptores de menores ingresos, que son la mayoría en toda sociedad, sostiene que: "Ninguna sociedad puede ser floreciente y feliz si la mayor parte de sus miembros son pobres y miserables. Es por añadidura, equitativo que quienes alimentan, visten, albergan al pueblo entero participen de tal modo en el producto de su propia labor que ellos también se encuentren razonablemente alimentados, vestidos y alojados". En el mismo capítulo sobre los salarios del trabajo señala que cuando hay una moderada abundancia (salarios altos) por sobre lo corriente es más probable que trabajen más porque se sienten animosos (págs. 80-81). Asimismo, este autor anota que aun cuando los salarios del trabajo se incrementen incidiendo en el precio de muchos productos y desalienten su consumo interno y externo, generalmente van acompañados de una mejora en la dotación de capital que acrecienta la productividad de la manufactura y se extiende a la sociedad y la economía en su conjunto. De esta forma, hay muchos productos que debido a estos adelantos se producen con menos trabajo que antes, de modo que el alza de los precios se compensa por la disminución en la cantidad de obreros necesarios (Smith, 1987, pág. 84).

A diferencia de Smith, Ricardo (1959) considera que el crecimiento económico es obra esencialmente de los capitalistas — que son la clase productiva de la sociedad-, quienes consumen una pequeña parte de lo que obtienen y dedican sus beneficios a la acumulación de capital. Se trata así de evitar que la tasa de beneficio llegue a reducirse a cero, donde los capitalistas no puedan acumular más, el crecimiento se detenga y el sistema alcance un estado estacionario (Pasinetti, 1978). Al respecto, la tasa de utilidades no podrá ser aumentada a menos que sean reducidos los salarios por medio del progreso técnico y el comercio exterior (en concreto, por la vía de las importaciones), que permitirían el abaratamiento de los bienes de primera necesidad 
(Ricardo, 1959, pág. 101). Tanto Malthus como el propio Ricardo se opondrán a la Ley de Pobres, ya que los salarios deberían dejarse a la libre competencia en el mercado y nunca ser controlados ni intervenidos por la legislatura. Estas leyes en lugar de enriquecer a los pobres, están calculadas para empobrecer a los ricos, ya que podrían crecer progresivamente hasta absorber los ingresos netos del país (Ricardo, 1959, págs. 80-81).

Marshall (1957) no va a superar la paradoja que eliminó toda la problemática analizada en la escuela neoclásica hasta la crisis de los años treinta del siglo $X X$. Por una parte, el autor reconoce que el aumento del nivel de vida del conjunto de la población elevaría tanto la eficiencia como el bienestar nacional (pág. 566), pero también puede "hacer al pueblo más desgraciado que antes" (pág. 567). A partir de él, con el énfasis en el análisis microeconómico y más adelante en la división entre la teoría del consumidor, por una parte, y la teoría del productor, por otra, se rompe todo vínculo entre la participación salarial y el nivel de actividad económica. A esta se sumará la ley de Say y posteriormente la de Walras para minimizar los efectos de esta evidente desvinculación.

La vinculación entre la participación salarial y el crecimiento económico reaparece con Keynes (1943), aunque de modo implícito a través de la propensión marginal a consumir y el multiplicador ${ }^{9}$, haciéndose más evidente cuando se establecen las recomendaciones generales de política económica. Los salarios son el componente principal del ingreso y el determinante de la propensión a consumir, y esta — a su vez-determinante del multiplicador del gasto. Sin embargo, la propensión a consumir no es constante para todos los niveles de ocupación, el nivel de apertura al comercio exterior y el contenido de mano de obra de la inversión pública, y depende además del comportamiento financiero de las empresas. También varía cuando se producen cambios en la proporción del ingreso total que va a dar a manos de los empresarios, quienes tienen una propensión marginal individual a consumir menor que el promedio para la comunidad en su conjunto (pág. 113). En el capítulo 24, Keynes señala con mayor evidencia que "es claro que una política fiscal de altos impuestos sobre herencias ${ }^{10}$ tiene el efecto de aumentar la propensión a consumir de la comunidad" (Keynes, 1943, pág. 329), la que será positiva para el crecimiento del capital, mientras

\footnotetext{
${ }^{9}$ Esto es evidenciado por Kaldor (1955).

${ }^{10}$ Los impuestos a los ingresos y las herencias redistribuirían ingresos de los estratos ricos a los pobres, elevando la propensión media a consumir de la sociedad y aumentando el multiplicador del gasto.
}

que la abstinencia de los ricos afecta al crecimiento de la riqueza.

Kalecki (1956) explicitará la vinculación de la distribución del ingreso, en particular de la masa salarial con respecto al ingreso, a partir del proceso de fijación de los precios determinados por la oferta y su posterior vinculación con la determinación del nivel de demanda y producción. En el primero de los casos, la participación de los salarios en el ingreso depende de: el grado de monopolio de la rama industrial en concreto, la relación salarios-gastos en materias primas en dicha actividad (relación técnica) y la estructura industrial (pág. 31). De esta forma, la participación de los salarios en el ingreso o producto depende inversamente de elementos como la diferenciación de productos (desarrollo de la promoción de ventas por medio de la publicidad), la existencia de procesos de concentración y la presencia de acuerdos tácitos o carteles; y directamente de la fuerza de los sindicatos y de otra variable relativa a la influencia que en el grado de monopolio tienen las variaciones de los gastos generales respecto de los costos primarios.

Kalecki determina el nivel de demanda y actividad económica a partir de los factores explicativos de las ganancias, que se derivan de la aplicación del principio de demanda efectiva por clase social: los capitalistas ganan lo que gastan, mientras que los asalariados gastan lo que ganan. De esta forma, las ganancias brutas estarían determinadas por sus niveles de consumo (dependientes del nivel de las ganancias), de inversión, el excedente de exportaciones (exportaciones menos importaciones) y el déficit presupuestal ${ }^{11}$. Posteriormente, asumiendo que la masa salarial depende del nivel de producto, este depende de las ganancias determinadas por un multiplicador que toma en cuenta la participación de la masa salarial en el producto. En síntesis, cuando aumenta la inversión privada, el excedente de exportaciones y el déficit presupuestal incrementan el producto, dependiendo de los multiplicadores vinculados a la propensión a consumir de los capitalistas y de la participación de la masa salarial en el producto. En la medida en que dichos multiplicadores aumenten, el producto se acrecentará mayormente, mientras que si disminuyen el crecimiento del producto será menor.

Kaldor (1955), bajo la lógica postkeynesiana, analiza las vinculaciones entre las ganancias, la inversión y el nivel de actividad económica, señalando que la participación

\footnotetext{
11 En la medida en que el sector privado de la economía recibe más de lo que paga en impuestos bajo la forma de gastos gubernamentales. Asimismo, en rigor, de las ganancias brutas habría que deducir el ahorro bruto de los capitalistas y de los trabajadores.
} 
de las ganancias en el producto depende de los niveles de inversión respecto del producto y de las diferentes propensiones a ahorrar de los asalariados y capitalistas ${ }^{12}$. En el caso extremo de que los asalariados no ahorren, las ganancias dependerán exclusivamente del nivel de inversión ajustada por el inverso de la propensión a ahorrar de los capitalistas, lo que sería equivalente al multiplicador del gasto tradicional. Al respecto, este autor destaca que su resultado es similar al de Kalecki, haciéndose más sensible cuando los trabajadores ahorran parte de sus salarios. Posteriormente, Pasinetti (1979) introduce una corrección relativa a que cuando un individuo ahorra parte de su ingreso debe conservarla como su propiedad. Así, los trabajadores que han ahorrado recibirán una porción de los beneficios totales. Lo interesante es que con esta corrección se obtienen similares resultados a los de Kaldor, pero sin considerar que la propensión a ahorrar de los asalariados sea igual a cero. La propensión de los trabajadores al ahorro no influye en la distribución del ingreso entre los beneficios y los salarios, y tampoco incide en la tasa de beneficio (Pasinetti, 1979, pág. 94).

Ros (2004) realiza un recuento de los mecanismos económicos y sociopolíticos mediante los cuales la desigualdad afecta al crecimiento económico. Entre los primeros, se destacan los efectos negativos de la desigualdad en el tamaño de mercado de las industrias

12 Que hay que entender como $1-C_{i}$, donde $C_{i}$ son las diferentes propensiones a consumir de los asalariados y los capitalistas.

\section{IV}

\section{Modelo básico}

Kalecki (1956) modela la determinación del nivel de actividad económica a partir del balance entre la oferta y la demanda agregada, modelo que es retomado por autores como Ocampo (1988), quien señala que, desde el enfoque del ingreso, este se puede descomponer en las ganancias después de la tributación $\left(G_{a}\right)$, los salarios $(S)$, las importaciones y los impuestos $(I)$. Por parte de la demanda, las variables equivalen al consumo de los propietarios $(C P)$, el consumo de los asalariados $(C A)$, la formación bruta de capital $(F)$, las exportaciones $(E)$ y el gasto público $(G)$. Para aproximar mejor el modelo a la realidad se supone que las importaciones pueden ser de bienes de consumo (IC), bienes intermedios (II) y de capital $(I B K)$ que se muestran en la ecuación (3). con rendimientos crecientes a escala o en la demanda agregada con impactos adversos en la inversión, y otros efectos indirectos que relacionan la menor desigualdad con el menor crecimiento de las tasas de fecundidad y de aumento demográfico. Asimismo, dentro de los efectos sociopolíticos, se destacan los grados de inestabilidad política y conflicto social provocados por la desigualdad, la polarización que socava el acuerdo en torno de las políticas económicas, lo que a su vez dificulta el manejo de conmociones externas ante la ausencia de consenso sobre la distribución de la carga del ajuste.

Más recientemente, a partir de los modelos postkeynesianos, se han establecido diferentes regímenes de crecimiento. En un extremo, el régimen basado en los salarios, que significa que un aumento en la participación salarial conduce a un alza de la demanda agregada y del PIB, ya que se acrecienta el consumo privado y este puede inducir a niveles de inversión superiores. Sin embargo, este régimen podría generar que las exportaciones fuesen menos competitivas y que la inversión se redujera. En el otro extremo, un régimen de la demanda basado en las ganancias significa que un incremento en la participación salarial conduce a una disminución de la demanda agregada, en el caso de que la inversión sea muy susceptible a una reducción en los márgenes de ganancia. Bajo esta lógica, una rentabilidad alta puede incentivar a las empresas a ampliar su capacidad productiva y aumentar su inversión. Los menores niveles de salarios contribuirían también al crecimiento de las exportaciones (Stockhammer, 2011).
Asimismo, en las ecuaciones (4), (5) y (6) los propietarios consumen una proporción $\left(\theta_{0}\right)$ de sus ganancias, las importaciones de bienes de capital son una proporción de la inversión total $\left(\theta_{1}\right)$ y el ahorro de los asalariados $(A s)$ es la diferencia entre sus salarios y el consumo. Despejando en (3) las ganancias e incorporando las otras ecuaciones, se obtiene (7).

$$
\begin{gathered}
Y=G a+S+I I+I C+I B K+I=C A+C P+F+E+G \\
C P=\theta_{0} G a \\
I B K=\theta_{1} F
\end{gathered}
$$




$$
S-C A=A s
$$

$$
G a\left(1-\theta_{0}\right)=F\left(1-\theta_{1}\right)+(G-I)+(E-I I-I C)-A s
$$

En la ecuación (8) se establece que los salarios mantienen una proporción del ingreso bruto del sector privado (wY) que es al mismo tiempo equivalente al ingreso bruto del sector privado menos las ganancias ${ }^{13}$. Luego, en la ecuación (9) se define que las importaciones de bienes intermedios son una proporción del producto nacional bruto $\left(\theta_{2}\right)$. La ecuación (10) se obtiene a partir de las ecuaciones (8) y (9) en (7). El producto estaría determinado por los componentes exógenos de la demanda incluidos en el numerador: exportaciones netas, formación bruta de capital en bienes nacionales y la diferencia entre el gasto público y los impuestos. En el denominador se incluye la participación salarial en el PIB, la propensión a consumir de los propietarios

${ }^{13}$ En ninguno de los casos, para simplificar, se considera el parámetro de la constante en las ecuaciones del consumo de los propietarios, en las importaciones de bienes intermedios y en las fluctuaciones de la participación de los asalariados respecto del producto. y la propensión a importar bienes intermedios que son parte del multiplicador del gasto.

Mediante la ecuación (11) se estima la contribución de la participación salarial al producto. Si aumenta la participación del salario en el producto este será mayor, a excepción de que el valor de los componentes exógenos de la demanda incorporados en el numerador sea negativo. Sin embargo, esto es poco probable, ya que el componente nacional de la formación bruta de capital debería ser neutralizado por el superávit fiscal, la presencia de exportaciones netas negativas y un elevado ahorro de los asalariados.

$$
\begin{gathered}
S=Y-G a=w Y \\
I I=\theta_{2} Y \ldots \\
Y=\frac{F\left(1-\theta_{1}\right)+(G-I)+(E-I C-A s)}{\left[(1-w)\left(1-\theta_{0}\right)+\theta_{2}\right]} \\
\frac{\partial Y}{\partial w}=\frac{\left(1-\theta_{0}\right)\left[F\left(1-\theta_{1}\right)+(G-I)+(E-I C-A s)\right]}{\left[(1-w)\left(1-\theta_{0}\right)+\theta_{2}\right]^{2}}
\end{gathered}
$$

\section{V}

\section{Evaluación empírica}

La primera evaluación que se realiza sobre las participaciones salariales y la evolución del PIB real de las diferentes economías latinoamericanas y el promedio regional calculado sobre la base de la información de ocho países es la prueba de causalidad de Granger. Cabe señalar que la información del PIB real está expresada en dólares constantes a precios del año 2000, información emanada del Banco Mundial y completada por la CEPAL ${ }^{14}$. La citada prueba es una prueba estadística para evaluar cuál es la causalidad dominante entre ambos grupos de variables: si la participación salarial es la que determina el

\footnotetext{
14 El Banco Mundial presenta ahora información desde el año 1960, mientras que la fuente de la CEPAL sirve para para el período anterior. Sin embargo, también es útil para los años recientes en el caso de la Argentina. Debe señalarse que en todos los casos este engarce se realizó a través de una regla de tres simple.
}

PIB o si el PIB es el que determina la participación salarial. En el modelo de la sección IV se revela que la relación causal de participación salarial a producto predomina por sobre la relación inversa (PIB causa a la Granger a la participación salarial) si la participación salarial es pequeña o si la economía tiene como mayores fuentes dinámicas al gobierno (consumo e inversión pública), a la inversión privada y al sector externo (exportaciones y apertura de importaciones). Sin embargo, conviene anotar que mediante la prueba de Granger se analiza la causalidad informativa, a diferencia de la intuitiva o fáctica.

En el cuadro 2 se presentan los resultados de la realización de la prueba de Granger a partir de la participación salarial en el PIB y la evolución del PIB real por país y para la región en todo el período bajo análisis. $\mathrm{Al}$ respecto, se ha optado por trabajar con la información 
Pruebas de causalidad de Granger entre la participación salarial y el PIB real de las economías de América Latina

(Filtro de Hodrick-Prescott: 3 rezagos)

Hipótesis nula

$\mathrm{N}^{\circ}$ de observaciones

Estadístico F

Probabilidad

PIB real de la Argentina no causa a la participación salarial

Participación salarial de la Argentina no causa al PIB real

PIB real de Bolivia (Estado Plurinacional de) no causa a la participación salarial

Participación salarial de Bolivia (Estado Plurinacional de) no causa al PIB real

PIB real del Brasil no causa a la participación salarial

Participación salarial del Brasil no causa al PIB real

PIB real de Chile no causa a la participación salarial

Participación salarial de Chile no causa al PIB real

PIB real de Colombia no causa a la participación salarial

Participación salarial de Colombia no causa al PIB real

PIB real de Costa Rica no causa a la participación salarial

Participación salarial de Costa Rica no causa al PIB real

PIB real del Ecuador no causa a la participación salarial

Participación salarial del Ecuador no causa al PIB real

PIB real de El Salvador no causa a la participación salarial

Participación salarial de El Salvador no causa al PIB real

PIB real de Honduras no causa a la participación salarial

Participación salarial de Honduras no causa al PIB real

PIB real de México no causa a la participación salarial

Participación salarial de México no causa al PIB real

PIB real de Panamá no causa a la participación salarial

Participación salarial de Panamá no causa al PIB real

PIB real del Paraguay no causa a la participación salarial

Participación salarial del Paraguay no causa al PIB real

PIB real del Perú no causa a la participación salarial

Participación salarial del Perú no causa al PIB real

PIB real del Uruguay no causa a la participación salarial

Participación salarial del Uruguay no causa al PIB real

PIB real de Venezuela (República Bolivariana de) no causa a la participación salarial

Participación salarial de Venezuela (República Bolivariana de) no causa al PIB real

PIB real de América Latina no causa a la participación salarial

Participación salarial de América Latina no causa al PIB real

\begin{tabular}{|c|c|c|}
\hline 59 & 1,41 & 0,25 \\
\hline 59 & 4,98 & 0,00 \\
\hline 49 & 3,49 & 0,02 \\
\hline 49 & 11,73 & 0,00 \\
\hline 59 & 3,19 & 0,03 \\
\hline 59 & 1,37 & 0,26 \\
\hline 58 & 1,37 & 0,26 \\
\hline 58 & 13,11 & 0,00 \\
\hline 58 & 8,57 & 0,00 \\
\hline 58 & 6,35 & 0,00 \\
\hline 55 & 2,85 & 0,05 \\
\hline 55 & 8,85 & 0,00 \\
\hline 56 & 5,91 & 0,00 \\
\hline 56 & 8,77 & 0,00 \\
\hline 49 & 6,46 & 0,00 \\
\hline 49 & 11,47 & 0,00 \\
\hline 59 & 11,34 & 0,00 \\
\hline 59 & 9,06 & 0,00 \\
\hline 59 & 11,61 & 0,00 \\
\hline 59 & 7,79 & 0,00 \\
\hline 59 & 9,35 & 0,00 \\
\hline 59 & 5,54 & 0,00 \\
\hline 46 & 42,27 & 0,00 \\
\hline 46 & 24,62 & 0,00 \\
\hline 59 & 3,73 & 0,02 \\
\hline 59 & 6,27 & 0,00 \\
\hline 54 & 4,30 & 0,01 \\
\hline 54 & 0,30 & 0,82 \\
\hline 51 & 6,98 & 0,00 \\
\hline 51 & 9,25 & 0,00 \\
\hline 58 & 3,69 & 0,02 \\
\hline 58 & 2,13 & 0,11 \\
\hline
\end{tabular}

Fuente: elaboración propia sobre la base de Banco Mundial, Comisión Económica para América Latina y el Caribe (cEPAL), Organización Internacional del Trabajo (OIT) y diversas fuentes locales.

PIB: producto interno bruto.

obtenida al aplicar el filtro de Hodrick-Prescott, que determina las tendencias no lineales de ambas series. Se opta por este criterio en lugar de considerar la información observada, debido a su elevada variabilidad ante factores de tipo coyuntural y otros estructurales no abordados en este trabajo. Debe también resaltarse que en la segunda sección del artículo se muestra que el resultado de la aplicación del filtro de Hodrick-Prescott es similar al que se obtendría al aplicar los promedios móviles y el indicador kernel de Epanechnikov.

En 8 de las 15 economías regionales se obtiene la vinculación prevista en la teoría: en todas las pruebas realizadas, la causalidad de la participación salarial hacia el PIB es más recurrente que la relación inversa. En otros cinco casos la relación dominante es a la inversa, pero no puede rechazarse que la participación salarial determine el PIB. Solo en un caso se manifiesta una relación de dominancia del PIB a la participación salarial. Al 95\% de confianza se rechaza que el PIB cause a la participación salarial en la Argentina, Bolivia (Estado Plurinacional de), Chile (con el mayor nivel de rechazo), Costa Rica, el Ecuador, El Salvador, el Perú y Venezuela (República Bolivariana de). No se rechaza que el PIB cause a la participación salarial en el Brasil, Colombia, Honduras, México, Panamá y el Paraguay. Solo se rechaza la relación causal de la participación salarial a PIB en el caso del Uruguay. En cuanto al conjunto de América Latina, donde el Brasil y México tienen un peso importante, no se rechaza al 95\% la causalidad del PIB a la participación salarial, pero tampoco se rechaza al 90\% la relación causal de la participación salarial al PIB.

En el cuadro 3 se presentan los resultados de las pruebas de causalidad de Granger para el conjunto de América Latina, considerando que el período 1950-2011 
CUADRO 3

Pruebas de causalidad de Granger entre la participación salarial y el PIB real de América Latina: 1950-1985 (3 rezagos) y 1986-2011 (2 rezagos)

\begin{tabular}{|c|c|c|c|}
\hline Hipótesis nula & $\begin{array}{l}\mathrm{N}^{\circ} \text { de } \\
\text { observaciones }\end{array}$ & Estadístico F & Probabilidad \\
\hline $\begin{array}{l}\text { PIB real de América Latina 1950-1985 no causa a la participación salarial } \\
\text { Participación salarial de América Latina no causa al PIB real }\end{array}$ & 33 & $\begin{array}{r}11,23 \\
3,70\end{array}$ & $\begin{array}{l}0,00 \\
0,02\end{array}$ \\
\hline $\begin{array}{l}\Delta \ln \text { (PIB real de América Latina) } 1950-1985 \text { no causa a la participación salarial } \\
\text { Participación salarial de América Latina no causa al } \Delta \ln \text { (PIB real de América Latina) }\end{array}$ & 32 & $\begin{array}{r}10,35 \\
5,36\end{array}$ & $\begin{array}{l}0,00 \\
0,01\end{array}$ \\
\hline $\begin{array}{l}\Delta \ln (\text { PIB real de América Latina) } 1950-1985 \text { no causa al } \Delta \ln \text { (participación salarial) } \\
\Delta \ln \text { (participación salarial de América Latina) no causa al } \Delta \ln (\text { PIB real) }\end{array}$ & 32 & $\begin{array}{l}4,74 \\
7,30\end{array}$ & $\begin{array}{l}0,01 \\
0,00\end{array}$ \\
\hline $\begin{array}{l}\text { PIB real de América Latina 1986-2011 no causa a la participación salarial } \\
\text { Participación salarial de América Latina no causa al PIB real }\end{array}$ & 23 & $\begin{array}{r}170,98 \\
16,71\end{array}$ & $\begin{array}{l}0,00 \\
0,00\end{array}$ \\
\hline $\begin{array}{l}\Delta \ln \text { (PIB real de América Latina) 1986-2011 no causa a la participación salarial } \\
\text { Participación salarial de América Latina no causa al } \Delta \ln \text { (PIB real de América Latina) }\end{array}$ & 22 & $\begin{array}{l}17,65 \\
60,87\end{array}$ & $\begin{array}{l}0,00 \\
0,00\end{array}$ \\
\hline $\begin{array}{l}\Delta \ln (\text { PIB real de América Latina) } 1986-2011 \text { no causa al } \Delta \ln \text { (participación salarial) } \\
\Delta \ln \text { (participación salarial América Latina) no causa al } \Delta \ln (\text { PIB real) }\end{array}$ & 22 & $\begin{array}{l}1,22 \\
9,53\end{array}$ & $\begin{array}{l}0,32 \\
0,00\end{array}$ \\
\hline
\end{tabular}

Fuente: elaboración propia sobre la base de Banco Mundial, Comisión Económica para América Latina y el Caribe (CEPAL), Organización Internacional del Trabajo (OIT) y diversas fuentes locales.

PIB: producto interno bruto.

$\Delta \mathrm{ln}$ : diferencias en logaritmos naturales.

se divida en dos subperíodos: 1950-1985 y 1986-2011, bajo el argumento de que a partir de la crisis de la deuda de los años ochenta se produjo un quiebre estructural que significó el cambio de un patrón productivo orientado hacia adentro — donde una mayor participación salarial era central al modelo- a otro orientado hacia afuera, en el que esta participación era menos importante. Al igual que en el cuadro 2, se está evaluando la causalidad dominante entre la información obtenida de la aplicación del filtro de Hodrick-Prescott de la participación salarial y el PIB real. Asimismo, se está considerando la causalidad de la variación porcentual del PIB real con la participación salarial y de la variación porcentual del PIB real con relación a la variación porcentual de la participación salarial. Al respecto, para los subperíodos 1950-1985 y 1986-2011 se observa que en el caso de las dos variaciones porcentuales se rechaza la hipótesis nula de que la participación salarial no causa al PIB real. En los casos de la vinculación entre el nivel de la participación salarial y el PIB real, como de la participación salarial y la variación porcentual tanto para 1950-2011 como para 1986-2011, no se rechaza en primera instancia que el PIB real cause a la participación salarial, aunque tampoco se rechaza que la participación salarial cause al pIB real.

En el gráfico 3 se observa la relación entre la tendencia no lineal de la participación salarial en lo que concierne al producto (eje izquierdo) y las variaciones porcentuales de la tendencia del PIB real (eje derecho), ambas calculadas luego de aplicar el filtro de HodrickPrescott. Al respecto, se determinan tres claras etapas en la vinculación entre estas dos variables. Una primera hasta inicios de los años ochenta, en que la correspondencia entre ambas es muy estrecha. Luego, a partir de los años ochenta e incluida la década de 1990, en que esta vinculación parece directa pero menor. Por último, desde inicios del siglo XXI, cuando se observa una relación opuesta entre la participación salarial y la variación porcentual del PIB real. En el gráfico 4 se advierte la evolución de la variación porcentual de la participación salarial con respecto a la variación porcentual en el PIB real para el mismo período de análisis. De igual forma que en el gráfico 3, durante las décadas de 1950, 1960 y 1970 la correspondencia entre ambas variables es directa, mientras que se aprecia una dinámica inversa en los años ochenta y noventa. Desde el año 2000 se observa una relación directa entre las variaciones porcentuales, pero esta vinculación es reducida.

En el cuadro 4 se presentan algunas regresiones seleccionadas de la variación porcentual del PIB real de América Latina en relación con la participación salarial, que es parte del multiplicador del gasto y los otros componentes exógenos de la demanda, de acuerdo con el modelo postkeynesiano que se presentó en la tercera sección de este estudio. Al respecto, se muestran cuatro de las regresiones seleccionadas donde la variación porcentual del PIB real es una función de la participación salarial del mismo período con un desfase, la sumatoria de la formación bruta de capital, las exportaciones de bienes y servicios y una variable ficticia para el conjunto de América Latina. Desafortunadamente, no hay información 
GRÁFICO 3

Participación salarial y crecimiento del PIB real en América Latina, 1950-2010 (Sobre la base de datos filtrados con Hodrick-Prescott)

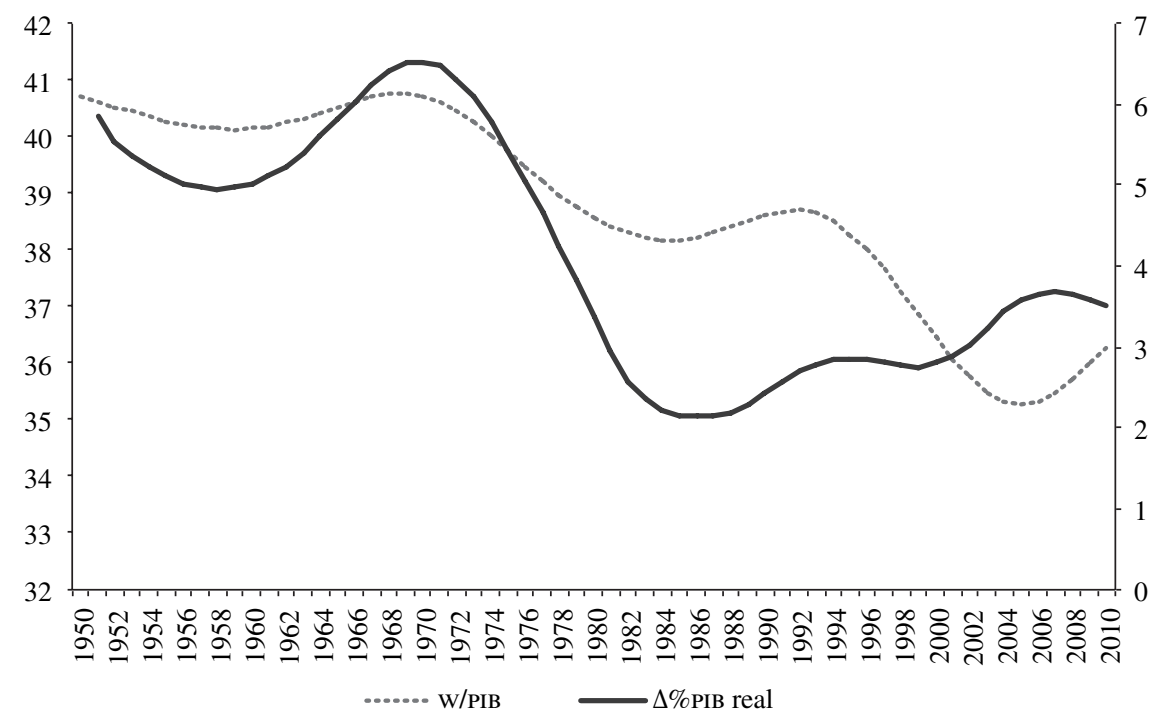

Fuente: elaboración propia sobre la base de Banco Mundial, Comisión Económica para América Latina y el Caribe (CEPAL), Organización Internacional del Trabajo (OIT) y diversas fuentes locales.

PIB: producto interno bruto.

W/PIB: participación de los salarios en el PIB.

$\Delta \%$ PIB real: variaciones porcentuales del PIB real en tendencia.

GRÁFICO 4

Variaciones porcentuales de la participación salarial y crecimiento del PIB real en América Latina, 1950-2010

(Sobre la base de datos filtrados con Hodrick-Prescott)

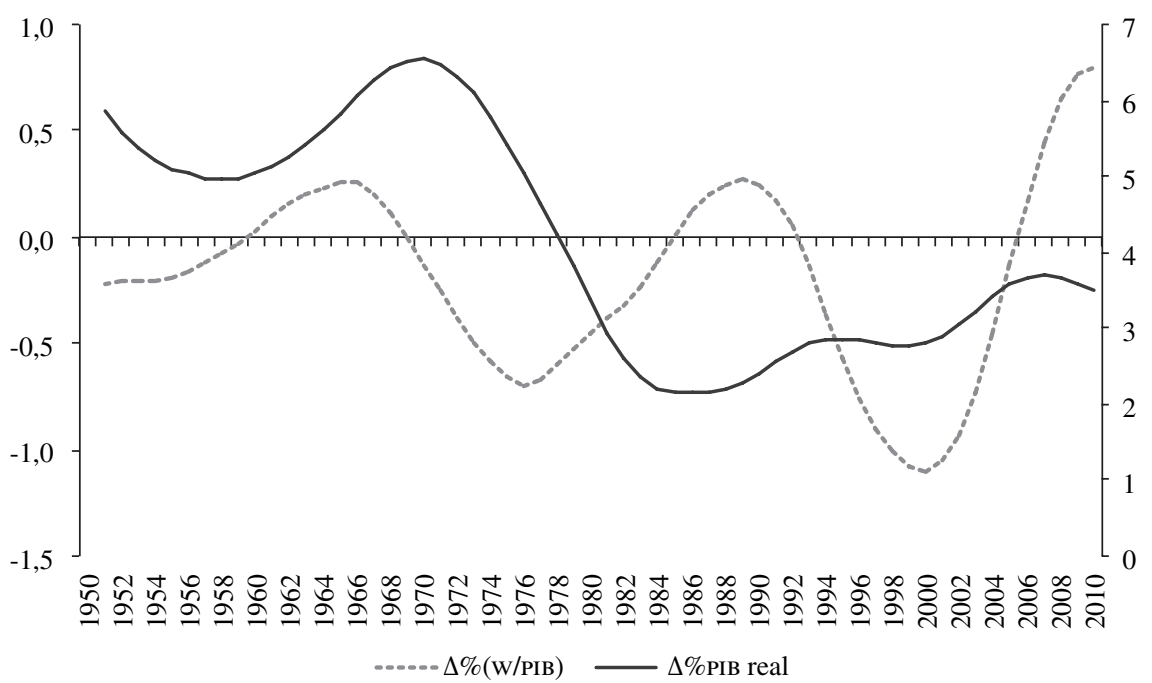

Fuente: elaboración propia sobre la base de Banco Mundial, Comisión Económica para América Latina y el Caribe (CEPAL), Organización Internacional del Trabajo (OIT) y diversas fuentes locales.

PIB: producto interno bruto.

$\Delta \%$ PIB real: variaciones porcentuales del PIB real en tendencia.

$\Delta \%$ (W/PIB): variaciones porcentuales de la participación salarial. 
CUADRO 4

Principales regresiones de la variación porcentual del PIB real y la participación salarial

\begin{tabular}{|c|c|c|c|c|}
\hline \multirow{2}{*}{ Variables independientes } & \multicolumn{4}{|c|}{ Variable dependiente: $\Delta \mathrm{Ln}$ (PIBR) } \\
\hline & Ecuación 1 & Ecuación 2 & Ecuación 3 & Ecuación 4 \\
\hline Constante & $\begin{array}{c}-0,059151 \\
(-1,474413)\end{array}$ & $\begin{array}{c}-0,045571 \\
(-1,27295)\end{array}$ & $\begin{array}{c}-0,061211 \\
(-1,613072)\end{array}$ & $\begin{array}{l}-0,046985 \\
(-1,38286)\end{array}$ \\
\hline Participación salarial & $\begin{array}{c}0,000776 \\
(2,083441)\end{array}$ & $\begin{array}{c}0,000691 \\
(2,08416)\end{array}$ & - & - \\
\hline Participación salarial (-1) & - & - & $\begin{array}{c}0,000803 \\
(2,257673)\end{array}$ & $\begin{array}{c}0,000709 \\
(2,234324)\end{array}$ \\
\hline$\Delta \mathrm{Ln}$ (formación bruta de capital) & $\begin{array}{c}0,269483 \\
(9,875241)\end{array}$ & $\begin{array}{c}0,237249 \\
(9,286399)\end{array}$ & $\begin{array}{r}0,269758 \\
(10,06362)\end{array}$ & $\begin{array}{c}0,237493 \\
(9,423314)\end{array}$ \\
\hline$\Delta \mathrm{Ln}$ (exportaciones de bienes y servicios) & $\begin{array}{c}0,078918 \\
(1,787322)\end{array}$ & $\begin{array}{c}0,117782 \\
(2,914614)\end{array}$ & $\begin{array}{c}0,063889 \\
(1,498404)\end{array}$ & $\begin{array}{c}0,10445 \\
(2,657407)\end{array}$ \\
\hline Variable ficticia*participación salarial & - & $\begin{array}{c}-0,000153 \\
(-3,995833)\end{array}$ & - & - \\
\hline Variable ficticia*participación salarial (-1) & - & - & - & $\begin{array}{l}-0,00015 \\
(-3,986638)\end{array}$ \\
\hline$R^{2}$ & 0,682682 & 0,754075 & 0,68645 & 0,755766 \\
\hline$\overline{R^{2}}$ & 0,665682 & 0,736189 & 0,669947 & 0,73832 \\
\hline $\mathrm{F}$ & 40,15965 & 42,16127 & 41,59639 & 43,32202 \\
\hline Durbin Watson & 1,683911 & 2,154472 & 1,653169 & 2,108096 \\
\hline $\mathrm{N}^{\circ}$ de observaciones & 60 & 60 & 61 & 61 \\
\hline
\end{tabular}

Fuente: elaboración propia sobre la base de Banco Mundial, Comisión Económica para América Latina y el Caribe (cEPAL), Organización Internacional del Trabajo (OIT) y diversas fuentes locales.

Nota: el número entre paréntesis es el valor de la prueba $t$-student. PIB: producto interno bruto.

$\Delta$ Ln (PIBR): logaritmos del PIB real.

sobre las finanzas públicas, propensiones a consumir y otras variables incorporadas en el modelo teórico para todo el período bajo análisis. La contribución de las importaciones a la variación porcentual del PIB real tuvo el signo negativo apropiado, pero este parámetro no fue significativamente diferente de cero.

Los resultados se presentan con y sin intercepto, donde todas las variables (incluida la participación salarial) tienen el signo esperado, con parámetros significativamente diferentes de cero. Las regresiones satisfacen las diferentes pruebas estadísticas y tienen una capacidad explicativa entre el $68 \%$ y el $76 \%$. En las ecuaciones (2) y (4) se incorpora una variable ficticia aplicada a la participación salarial, que asume valor 1 entre 1980 y 2000 y valor 0 para el resto del período, y que reflejaría la existencia de otras políticas como la de ingreso, que - a partir de la crisis de la deuda y los años noventa-implicó rezagos en los ajustes del salario mínimo y de los salarios del gobierno, que incidieron negativamente en la contribución de la participación salarial en el crecimiento del PIB real. Estas variables ficticias mejoran la bondad de ajuste de los modelos, un elemento de la realidad de las políticas de ajuste de América Latina. Conviene señalar que tampoco existe información sobre los salarios reales para todo el período bajo análisis. En todos los casos, se concluye que la participación salarial y la tasa de crecimiento de la formación bruta de capital y de las exportaciones no se rechazan como variables explicativas del crecimiento del producto real de América Latina. 


\section{VI}

\section{Conclusiones}

En este trabajo se completan y profundizan otros estudios previos sobre la participación salarial en 15 de las economías de América Latina y en relación con toda la región para el período 1950-2010. Al respecto, cabe subrayar que el proceso de construcción de las estadísticas fue arduo, debido a que en la mayoría de las economías la problemática de la distribución funcional del ingreso ha sido soslayada y sustituida por la referida a la distribución personal. Asimismo, de acuerdo con la macroeconomía de la corriente ortodoxa, la participación de los salarios en el producto, la evolución de los salarios reales y el nivel de empleo desafortunadamente constituyen ahora variables residuales para explicar el nivel de actividad y crecimiento económico.

Se realiza un breve análisis sobre la vinculación de la participación salarial respecto del nivel de actividad y crecimiento económico desde Smith, donde esta vinculación es positiva. Posteriormente, el análisis de esta relación se diluye en Ricardo y en Marshall, que da inicio a la escuela neoclásica donde esta relación es soslayada. El vínculo reaparece implícitamente con Keynes, para hacerse transparente en los autores postkeynesianos como Kalecki, Kaldor, Pasinetti y Ros. La macroeconomía moderna sigue en la tradición neoclásica con excepción de autores como Krugman (2012) y Stiglitz (2012), que rehabilitan la importancia de la distribución del ingreso para explicar la evolución de economías particulares y de la economía mundial.

Bajo la tradición de Kalecki se desarrolla un modelo que permite explicar el nivel de actividad y crecimiento económico en función del multiplicador del gasto y los componentes exógenos de la demanda. La presencia de la participación salarial en el producto es central en el multiplicador del gasto. Asimismo, queda claro que una variación positiva en esta conducirá a un incremento del nivel del PIB real. Sin embargo, hay que resaltar que el resultado final en términos del producto depende también de los valores de los componentes exógenos de la demanda.
Mientras se obtienen resultados claros sobre la tendencia no lineal de la evolución de la participación salarial en América Latina entre 1950-2010, se observan resultados diferentes para los distintos países de la región. En suma, son evidentes los dos ciclos, con un mayor nivel a finales de los años sesenta e inicios de los años setenta, un valor mínimo en los años ochenta, otro aumento menor de nivel de participación salarial en los años noventa, y una nueva caída hasta 2005 para constatarse nuevamente una tendencia creciente. Los niveles y fluctuaciones de la participación salarial en cada economía se explican por un conjunto de factores de naturaleza estructural vinculados al modelo de acumulación, y a factores económicos, sociales y políticos a lo largo del tiempo cuyo análisis rebasaría los alcances de este documento.

La relación de causalidad dominante va de la participación salarial al nivel de actividad y crecimiento económico, aunque no se rechaza la causalidad en sentido contrario para determinados países en particular. La causalidad de la variación porcentual de la participación salarial al crecimiento es mayor que cuando se trabaja con las variables en términos de niveles. A nivel regional, se observa una alta correspondencia entre las participaciones de los salarios en el PIB respecto de las variaciones porcentuales del PIB hasta los años ochenta. A partir de entonces las vinculaciones son menores. Lo mismo ocurre cuando se analiza la variación porcentual de la participación salarial respecto de las variaciones del PIB, aunque esta vinculación se recupera ligeramente a partir del siglo XXI. Cuando se realiza el análisis de regresión en la lógica postkeynesiana, no se rechaza la hipótesis de que la participación salarial en el producto real contribuyó a explicar las variaciones al alza y a la baja del PIB real en América Latina en el período bajo análisis. Sin embargo, se ratifica que su contribución es menor desde los años ochenta. Estos resultados pueden ser indicio de una transición del régimen de demanda basado en los salarios a otro basado en las ganancias. Sin embargo, el análisis de esta problemática sobrepasaría los alcances de este artículo. 


\section{VII}

\section{Anexo metodológico}

En el caso de la Argentina, se cuenta con la metodología e información de Graña (2007) hasta 2005, a la que se agregó la información oficial del INDEC (2013) hasta 2007. Sin embargo, se pudo contactar al autor, miembro del Centro de Estudios sobre Población, Empleo y Desarrollo (CEPED) de la Universidad de Buenos Aires, quien proporcionó la serie completa hasta 2011, que coincide con la información oficial hasta el año 2007. En el caso de Bolivia (Estado Plurinacional de), los períodos 19691982 y 1984-1986 corresponden a CEPAL $(1979,1981$ y 1990), y 1988-2008 a CEPAL (2013), antecedidos para el período 1960-1968 con la información de la OIT (1970). Para el período 2009-2011 se utilizan directamente datos del Instituto Nacional de Estadística de Bolivia (Estado Plurinacional de). En los años 1983 y 1987 se aplicó la ecuación (2) de la segunda sección del documento. Los datos de salarios medios reales utilizados corresponden a CEPAL (2013), los de nivel general de empleo son de la OIT (1988) y los del PIB real provienen de los Indicadores del Desarrollo Mundial (Banco Mundial, 2013). En el caso del Brasil, la información respecto del período 1990-2009 provino de CEPAL (2013), mientras que la de 1950 a 1989 fue obtenida de Medialdea (2012). Para los años 2010 y 2011 se consideró la metodología descrita anteriormente, siendo CEPAL (2013) la fuente de información sobre los salarios reales promedio, oIT (2012) la del empleo y Banco Mundial (2013) la del PIB.

La fuente de información sobre Chile respecto del período 1960-2010 corresponde a CEPAL (2013) y para el período 1950-1959 se utilizaron las tasas de crecimiento de la participación salarial sobre la base del trabajo de Rodríguez (2012), ya que estas se expresaban en relación con el ingreso nacional y no con el PIB. Para el período 1965-1969, en el caso de Colombia, se utilizó la información de CEPAL (1976) y para 1970-2010 de CEPAL (2013). Para el período 1950-1964, la fuente fue OIT $(1955,1960,1965$ y 1970). En el caso de Costa Rica, entre 1961 y 1998 se utilizó como fuente CEPAL (1976, 1999) y CEPAL (2013); el período 1999-2011 se completó con datos del Banco Central de Costa Rica (2013). El período 1953-1960 fue completado sobre la base de oit (1960, 1965 y 1970). En el caso del Ecuador, el período 1990-1996 se basó en CEPAL (1999), y el lapso 1970-1989 en CEPAL (2013). Para el período 1997-2011 se utilizó la información contenida en la Encuesta Nacional de Empleo, Desempleo y Subempleo respecto del período 1996-2012 (INDEC, 2013). Por último, la información sobre el período 1953-1969 corresponde a Neira Barría (2010).

Los datos de El Salvador para el período 1960-2011 corresponden a Durán y otros (2010), en que se consigna la información respecto de sueldos y salarios corrientes sobre la base de la información proporcionada por el Instituto Salvadoreño de Seguridad Social y Encuestas de Hogares de Propósitos Múltiples. En el caso de Honduras, toda la información acerca del período 1950-2011 proviene de CEPAL (2013). La información concerniente al período 1970-2011 con respecto a México corresponde a datos de cePAl (2013). También en el caso de México, para el período 1950-1969 se utilizó información de Hernández Laos (2000), la que se enlazó con la anterior mediante tasas de crecimiento. En el caso de Panamá, la información sobre el período 1960-2011 se obtuvo de CEPAL (2013), mientras que la del período 1950-1959 fue completada utilizando las tasas de crecimiento de la participación salarial proporcionadas por el Banco Nacional de Panamá (2013). En el caso del Paraguay, la información sobre el período 1962-1969 emanó de CEPAL (1976), mientras que la del lapso 1970-2007 corresponde a CEPAL (2013). Se completa el período 2008-2010 con la información de la Cuenta de Generación del Ingreso Primario elaborada por el Banco Central del Paraguay (2013).

En el caso del Perú, los datos respecto del período 1965-2010 provienen de CEPAL (2013) y los del lapso 1950-1964 corresponden a la información procesada por Alarco y Del Hierro (1989), sobre la base de las Cuentas Nacionales elaboradas por el Banco Central de Reserva del Perú; en tanto que los datos acerca del año 2011 corresponden al Instituto Nacional de Estadística e Informática (INEI, 2013). Respecto del Uruguay, la información sobre el período 1955-1996 se obtuvo del Programa de las Naciones Unidas para el Desarrollo (PNUD, 2008). La del período 1997-2005 emanó del Banco Central del Uruguay (2013). En cuanto a los años comprendidos entre 2006 y 2011, se empleó el método señalado anteriormente considerando como fuente de los salarios reales a CEPAL (2013), del nivel de empleo a OIT (2013a) y del PIB real al Banco Mundial (2013). Finalmente, en el caso de Venezuela (República Bolivariana de), la fuente de información acerca del período 1970-2010 fue CEPAL (2013) y el Banco Central de Venezuela (2013) para el lapso 1957-1969. 


\section{Bibliografía}

Alarco, Germán y Patricia del Hierro (1989), "Perú 1985-1988: De la redistribución a la reconcentración del ingreso", Economía de América Latina, vol. 18-19, México, D.F., Centro de Investigación y Docencia Económicas.

Banco Central de Costa Rica (2013), Cuenta de generación del ingreso - Cálculo del PIB por el método del ingreso, San José.

Banco Central de Venezuela (2013), Producto y gasto interno bruto, Caracas.

Banco Central del Paraguay (2013), Cuenta de generación del ingreso primario, Asunción.

Banco Central del Uruguay (2013), Producto interno bruto según fuentes generadoras de ingreso, serie anual, precios corrientes, Montevideo.

Banco Mundial (2013), World Development Indicators [en línea] http://data.worldbank.org/data-catalog/world-developmentindicators.

Banco Nacional de Panamá (2013), Cuenta 2. Ingreso Nacional: Años 1946-1961, Ciudad de Panamá.

Bértola, Luis y otros (2008), "Income distribution in the Latin American Southern Cone during the first globalization boom, ca: 1870-1920", Working Papers in Economic History, Madrid, Universidad Carlos III, abril.

CEPAL (Comisión Económica para América Latina y el Caribe) (2013), "Estadísticas e indicadores", cepalstat: Base de Datos y Publicaciones Estadísticas [en línea] http://estadisticas. cepal.org/cepalstat/WEB_CEPALSTAT/estadisticasIndicadores. asp?idioma $=$ e.

(2003), Anuario Estadístico de América Latina y el Caribe, 2002 (LC/G.2190-P), Santiago de Chile. Publicación de las Naciones Unidas, $\mathrm{N}^{\circ}$ de venta: E/S.03.II.G.1.

(1999), Anuario Estadístico de América Latina y el Caribe, 1998 (LC/G.2043-P), Santiago de Chile. Publicación de las Naciones Unidas, $\mathrm{N}^{\circ}$ de venta: E/S.99.II.G.1.

(1990), Anuario Estadístico de América Latina y el Caribe. Edición 1989 (LC/G.1606-P), Santiago de Chile. Publicación de las Naciones Unidas, $\mathrm{N}^{\circ}$ de venta: E/S.90.II.G.1.

(1981), Anuario Estadístico de América Latina, 1980 (E/CePal/G.1210), Santiago de Chile. Publicación de las Naciones Unidas, $\mathrm{N}^{\circ}$ de venta: S/E.81.II.G.5.

(1979), Anuario Estadístico de América Latina, 1978 (E/CEPAL/1086), Santiago de Chile. Publicación de las Naciones Unidas, $\mathrm{N}^{\circ}$ de venta: S/E.79.II.G.3.

(1976), Anuario Estadístico de América Latina, 1975 (E/CEPAL/1013), Santiago de Chile. Publicación de las Naciones Unidas, $\mathrm{N}^{\circ}$ de venta: E/S.77.II.G.4.

CEPAL/OIT (Comisión Económica para América Latina y el Caribe/ Organización Internacional del Trabajo) (2012), "Productividad laboral y distribución", Coyuntura Laboral en América Latina y el Caribe, $\mathrm{N}^{\circ}$ 6, Santiago de Chile, mayo [en línea] http:// www.ilo.org/wcmsp5/groups/public/---americas/---ro-lima/--sro-santiago/documents/publication/wcms_190865.pdf.

Durán, Tania y otros (2010), "Las políticas de ajuste estructural en El Salvador: Impacto sobre la inversión y distribución (19902010)", trabajo preparado para optar al grado de Licenciada en Economía, Antiguo Cuscatlán, Universidad Centroamericana José Simeón Cañas.

Frankema, Ewout (2009), "Reconstructing Labour Income Shares in Argentina, Brazil and Mexico, 1870-2000", Utrecht, Universidad de Utrecht.

Graña, Juan (2007), "Distribución funcional del ingreso en la Argentina. 1935-2005", Documento de Trabajo, $\mathrm{N}^{\circ}$ 8, Centro de Estudios sobre Población, Empleo y Desarrollo (CEPED).

Hernández Laos, Enrique (2000), "Políticas de estabilización y ajuste y distribución funcional del ingreso en México", Revista Comercio Exterior, México, D.F., febrero.
INDEC (Instituto Nacional de Estadística y Censos) (2013), "Encuesta Nacional de Empleo y Desempleo", Quito.

INEI (Instituto Nacional de Estadística e Informática) (2013), "Cuentas nacionales", Series Nacionales [en línea] http://series.inei.gob. pe:8080/sirtod-series/

Kaldor, Nicholas (1955), "Alternative theories of distribution", The Review of Economic Studies, vol. 23, № 2, Oxford, Oxford University Press.

Kalecki, Michal (1956), Teoría de la dinámica económica: Ensayo sobre los movimientos cíclicos y a largo plazo de la economía capitalista, México, D.F., Fondo de Cultura Económica.

Keynes, J.M. (1943), Teoría general de la ocupación el interés y el dinero, México, D.F., Fondo de Cultura Económica.

Krugman, Paul (2012), ;Detengamos esta crisis YA!, México, D.F., Editorial Paidós.

Kuznets, Simon (1955), "Economic growth and income inequality", American Economic Review, vol. 65, $\mathrm{N}^{\circ}$ 1, Nashville, Tennessee, American Economic Association, marzo.

Lindenboim, Javier (2008), "Distribución funcional del ingreso, un tema olvidado que reclama atención", Problemas del desarrollo, vol. 39, $\mathrm{N}^{\circ}$ 153, México, D.F., Universidad Nacional Autónoma de México.

Marshall, Alfred (1957), Principios de economía, Madrid, Aguilar.

Medialdea, Bibiana (2012), "Límites estructurales al desarrollo económico: Brasil (1950-2005)", Problemas del desarrollo, vol. 43, N 171, México, D.F., Universidad Nacional Autónoma de México.

Neira Barría, Vicente (2010), Distribución factorial del ingreso en América Latina, 1950-2000: Nuevas series a partir de las cuentas nacionales, Barcelona, Universitat Pompeu Fabra.

Ocampo, José Antonio (1988), "De Keynes al análisis poskeynesiano", Economía poskeynesiana, México, D.F., Fondo de Cultura Económica.

Ocampo, José Antonio y Juan Martin (coords.) (2004), América Latina y el Caribe en la era global, Bogotá, CEPAL/Alfaomega.

OIT (Organización Internacional del Trabajo) (2013a), Informe mundial sobre salarios 2012/2013. Los salarios y el crecimiento equitativo, Ginebra.

(2013b), Key Indicators of the Labor Market, Ginebra.

(2012), Panorama Laboral 2012, Lima, Oficina Regional para América Latina y el Caribe.

(1988), Anuario de Estadísticas del Trabajo, Ginebra. (1970), Anuario de Estadísticas del Trabajo, Ginebra. (1965), Anuario de Estadísticas del Trabajo, Ginebra. (1960), Anuario de Estadísticas del Trabajo, Ginebra. (1955), Anuario de Estadísticas del trabajo, Ginebra.

Pasinetti, Luigi (1979), "Beneficio y crecimiento", Economía del crecimiento. Selección de Amartya Sen, México, D.F., Fondo de Cultura Económica.

(1978), Crecimiento económico y distribución de la renta, Madrid, Alianza Editorial.

Pérez Caldentey, Esteban y Matías Vernengo (2013), "Wage and Profit-led Growth: The Limits to Neo-Kaleckian Models and a Kaldorian Proposal" [en línea] http://www.levyinstitute.org/ pubs/wp_775.pdf.

PNUD (Programa de las Naciones Unidas para el Desarrollo) (2008), Desarrollo humano en Uruguay 2008: Políticas y desarrollo humano, Montevideo.

Ricardo, David (1959), Principios de economía política y tributación, México, D.F., Fondo de Cultura Económica.

Rodríguez, Javier (2012), "Estimando la distribución del ingreso en Chile durante la industrialización dirigida por el Estado. Metodología y resultados preliminares", XVII Jornadas Anuales de Economía, Montevideo, Banco Central del Uruguay, noviembre. 
Ros, Jaime (2004), "El crecimiento económico en México y Centroamérica: Desempeño reciente y perspectivas", Serie Estudios y Perspectivas, $\mathrm{N}^{\circ} 18$ (LC/L.2124-P) México, D.F., sede subregional de la CEPAL en México. Publicación de las Naciones Unidas, $\mathrm{N}^{\circ}$ de venta: S.04.II.G.48.

Saez, Emmanuel (2012), "Striking it Richer: The Evolution of Top Incomes in the United States (Updated with 2009 and 2010 estimates)" [en línea] http://elsa.berkeley.edu/ saez/saezUStopincomes-2010.pdf.
Smith, Adam (1987), Investigación sobre la naturaleza y causa de la riqueza de las naciones, México, D.F., Fondo de Cultura Económica.

Stiglitz, Joseph (2012), El precio de la desigualdad, Buenos Aires, Taurus.

Stockhammer, Engelbert (2011), "Crecimiento basado en los salarios: Introducción”, Hacia una recuperación sostenible: Por una política de crecimiento basada en los salarios, Boletín Internacional de Investigación Sindical, vol. 3, N² 2, Ginebra, Oficina Internacional del Trabajo. 